\title{
Lexical access in bilinguals
}

\author{
ALFONSO CARAMAZZA and ISABEL BRONES \\ Johns Hopkins University, Baltimore, Maryland 21218
}

\begin{abstract}
Spanish-English bilinguals were asked to determine whether a string of letters formed a word in their languages. Three separate conditions were used: two conditions blocked by language and a mixed-language condition. Some of the words were cognates, words with the same spelling and meaning in the two languages. There were no differences between blocked and mixed conditions; cognates were responded to with equal facility in all conditions, and there was an interaction of Cognates and Noncognates by Weak and Strong Language. These results were interpreted as supporting a direct graphemic lexical access model.
\end{abstract}

The study of bilingual speakers, in addition to providing answers to substantive questions about the representation and processing of the two languages of the bilingual, can also provide general constraints on language processing models. That is, one can only address questions about bilingual processing by implicitly or explicitly assuming some general model of language functioning. By exploring how bilinguals access lexical information, we can simultaneously address questions about language representation in bilinguals and information processing models of lexical access.

A central issue in bilingual research is the relationship between the bilingual's two languages and, in particular, the two lexicons. Two hypotheses have been proposed. The separate hypothesis maintains that the two languages are stored separately in memory and that information acquired in one language is only available in the other through translation (Kolers, 1963; Tulving \& Colotla, 1970). The shared hypothesis holds that information is stored in a single semantic memory representation with language-specific "tags" (Kolers, 1966; Lopez \& Young, 1974; Young \& Navar, 1968).

Recent studies directed at assessing lexical-semantic processing by bilinguals have disconfirmed various versions of the separate storage hypothesis (Caramazza \& Brones, Note 1; Wolf, McCloskey, \& Glucksberg, Note 2). And, in any case, until there is strong evidence to the contrary, it is advisable to adopt the more parsimonious position that bilinguals have a single semantic network or structure with separate lexical entries for the two languages (Macnamara, 1967).

The issue motivating the present research concerns how bilinguals access lexical information. In deciding whether a string of letters is a word, a minimum

The research reported here was supported in part by Biomedical Sciences Support Grant 5 S07 RR07041-12. The authors thank Hiram Brownell and Michael McCloskey for their helpful comments on an earlier version of this paper. Reprint requests should be sent to Alfonso Caramazza, Department of Psychology, Johns Hopkins University, Baltimore, Maryland 21218. sequence of events is the following. The stimulus is encoded at a phonological level, at a graphemic level, or both. If the stimulus conforms to the phonological and/or graphemic rules of the language, then enter the lexicon and determine whether the presented string matches a string in memory and respond. This description allows at least two distinct processing models. One serial model proceeds from a graphemic to a phonological representation before information can be accessed from the lexicon. A second model allows parallel entries from the phonological and graphemic representations, with either being sufficient to determine whether a matching string is available in the lexicon. The issue of which of these two models best represents lexical access with printed words is not yet resolved.

It is possible to address the issue of serial vs. parallel access by considering how bilinguals make lexical decisions. Thus, consider in this context a lexical decision task. A bilingual subject is briefly shown a string of letters and he is asked to determine whether the string forms a word in one of his languages. In one condition, words are all from one language, and the subject is instructed to determine whether the letter string forms a word in that language. In another condition, the words are from the bilingual's other language. In a third condition, a mixed list of words from the two languages is presented. In addition, the lists of words contain a number of cognates, words spelled the same and with the same meaning in the two languages. The inclusion of cognates permits a clear differentiation between the two lexical access models described.

The critical factor is that cognates have identical graphemic structures but different phonological structures in the two languages; they have different pronunciations in the two languages. For example, "general" is pronounced džénaral in English but xenerál in Spanish. Given this property, if the serial model is correct, then access of cognates in the lexicon will be through the phonological representations of the words, which are clearly different in the two languages. Further, given that lexical access is slower in the weaker of the 
two languages of the bilingual, it is predicted that reaction time to access cognates in the blocked list of the weaker language should not be different from other words in that language and should be slower than cognates and noncognates in the blocked list of the stronger language. That is, in this model, the phonological representation specifies a unique entry in the lexicon of the weaker language and should be processed as any other word of that language. In contrast, the direct graphemic access model (parallel model) predicts a difference between cognates and noncognates in the blocked list of the weaker language and no difference among cognates for the three lists (two blocked and one mixed list). In this model, since access can proceed from the graphemic representation, both language entries will be activated, producing a facilitatory effect through the common semantic representation. Thus, reaction times to cognates should be at least as fast as the fastest condition in the experiment.

\section{METHOD}

\section{Subjects}

The subjects were 12 Spanish-English bilinguals, of whom 8 were college students, 3 were housewives, and 1 was a physician. They were all native Spanish speakers who rated themselves at least 4 on a 7-point scale of bilingualism. The mean self-rating was 5.5. All of the subjects had been in an English-speaking environment for at least 1 year.

Subjects were assigned to conditions by a predetermined random sequence, according to order of appearance for the experiment.

\section{Materials}

Two lists, one English and one Spanish, were constructed in the following way: Each list consisted of 60 words, of which 15 were cognates, and 60 nonwords. Thus, the English and Spanish lists each consisted of 120 stimuli. Both lists combined were used in the mixed-language mode of presentation.

All letter strings were 4 to 10 letters long. The nonwords looked and sounded like English words in the English list and like Spanish words in the Spanish list, but they were not members of either language (i.e., they did not appear in Webster's Third New International Dictionary, 1971, or the Diccionario de la Real Academia Espanola, 1970). The mean word frequencies were $88.6 /$ million for the English words and $88.7 /$ million for the English equivalents of the Spanish words. Cognates were assigned randomly to each list, and their mean frequency was $87.5 /$ million for the English list and 88.8/million for the Spanish list (Kučera \& Francis, 1967).

Four practice lists were also constructed, consisting of 10 words and 10 nonwords each, and different from those used for the experiment proper. No cognates were included in these lists.

\section{Apparatus}

Stimuli were presented on a DEC-VR14 fast-decay CRT display controlled by a PDP-11/20 computer. The letters were formed by activating the appropriate dots in a 5 by 7 dot matrix. The horizontal visual angles for both the word and nonword stimuli ranged from $4 \mathrm{deg}$ for the 4-letter stimuli to $10 \mathrm{deg}$ for the 10 -letter stimuli. All stimuli subtended a vertical visual angle of approximately $1.2 \mathrm{deg}$. Stimuli were presented in the center of the display screen.

\section{Procedure}

Each experimental session lasted approximately $30 \mathrm{~min}$. There were four blocks of 120 trials each. A block of trials consisted of the presentation of one of the lists: Spanish, English, or mixed. The mixed list was divided in half and given in two separate blocks. The order of presentation of the blocks was counterbalanced across subjects.

A trial began with a fixation point displayed in the center of the display screen for $1 \mathrm{sec}$ as a "ready" signal. A row of letters then appeared, situated so that the middle letter fell over the fixation area. Subjects were to press one key if the row of letters formed an English or a Spanish word in the third. They were to press a different key if the row of letters was not a word. The display terminated and the timer stopped with the subject's response. Response keys were counterbalanced across preferred hands. The computer recorded the reaction times and randomized the presentation of the words within each list separately for each subject, with the restriction that no cognates were to appear in the first 10 trials of each block.

Instructions were read in English, and subjects were encouraged to respond quickly and accurately. Twenty practice trials were given before each block to get the subject used to the task demands of the experiment in each mode of presentation. No cognates were presented in the practice session.

\section{RESULTS AND DISCUSSION}

Mean reaction times for list types and items are presented in Table 1 . The overall error rate was $2.4 \%$, and there were no systematic differences in errors across conditions or items. All analyses were carried out on reaction time data only.

The comparisons of interest were (1) performance on blocked vs. mixed lists, and (2) performance on cognates vs. noncognates in weak and strong language. Analyses of variance, one for Spanish and one for English, were performed on the data with list condition (blocked vs. mixed) and items (cognates vs. noncognates vs. nonwords) as factors. List condition was not significant either in the English or in the Spanish mode $(\mathrm{F}<1$ in both cases). Item type was significant in both the Spanish and the English modes $[F(2,22)=56.32$, $\mathrm{p}<.001$, and $\mathrm{F}(2,22)=59.78, \mathrm{p}<.001$, respectively] In the Spanish mode the differences are between the words and nonwords, while in the English mode there are differences among cognates, noncognates, and nonwords. The remaining result, the interaction of List Condition by Item Type, was not reliable either in the Spanish $(F<1)$ or in the English $[F(2,22)=3.339$, $.10>p>.05]$ mode, although it approached significance in the English mode. Inspection of the data reveals that the near-significant interaction in the English mode results from having averaged across "English" and "Spanish" nonwords. Because of the way in which the data recording program was written, we were unable to separate these two types of nonwords. However, a t test comparing nonwords in the Spanish and English blocked

Table 1

Mean Reaction Times in Milliseconds

\begin{tabular}{lcccc}
\hline Block & $\begin{array}{c}\text { English } \\
\text { Words }\end{array}$ & $\begin{array}{c}\text { Spanish } \\
\text { Words }\end{array}$ & Cognates & Nonwords \\
\hline English & 673 & & 631 & 811 \\
Spanish & & 629 & 621 & 739 \\
Mixed & 674 & 616 & 612 & 755 \\
\hline
\end{tabular}


lists was highly reliable $[t(11)=32.4, p<.001]$. This result suggests that lexical search is slower through the weaker language lexicon not only for words but also for nonwords. In general, the slower reaction times for nonwords across conditions is consistent with Rubenstein, Garfield, and Millikin's (1970) suggestion that memory search when nonwords are presented is exhaustive and/or has a longer exit parameter when a match is not found.

The other analysis carried out was a comparison of cognates and noncognates in the two blocked list conditions. An analysis of variance with cognates and noncognates and English and Spanish modes as factors resulted in a significant main effect for condition $[F(1,11)=14.67, p<.01]$. The interaction was also reliable $[F(1,11)=6.1, p<.05]$. Subsequent post hoc tests (Newman-Keuls) revealed that the English noncognates differed significantly from the other three conditions, which did not differ from each other. This result provides strong support to the direct graphemic access mode; that is, lexical access does not necessarily go through a phonological look-up procedure.

\section{CONCLUSIONS}

The pattern of results we have reported is consistent with a bilingual lexical access model that allows direct access through graphemic representations (Baron, 1973; Saffran \& Marin, 1977). This conclusion makes substantive claims both about bilingual processing and lexical access in general. It is, of course, quite possible that bilingual speakers have developed special mechanisms for processing language information that are different from those employed by unilingual speakers. In such a case it would be unjustified to draw conclusions from research on bilinguals about unilingual functioning. However, until a more complete bilingual processing model has been developed that includes potential differences in processing, it is more parsimonious to assume that bilingual processes are simply "added" to the processing apparatus of unilingual speakers.

One other issue that needs to be addressed is the reaction time differences between the English and the Spanish mode. It was found that the weaker language is processed more slowly than the stronger language. Two explanations are possible. One is that subjects translate the weaker language in to the stronger language before responding affirmatively. This possibility seems quite implausible and does not explain the slower reaction times for the nonwords in this condition. The other is a frequencybased explanation (Broadbent, 1967). That is, subjects respond faster to more frequent words in their language(s). Since the bilinguals we tested are dominant in Spanish, their familiarity with Spanish words is greater than that for English words. Note, however, that the frequency explanation is orthogonal to the conclusions we have reached about lexical access. The frequency explanation by itself cannot explain why cognates in the English-mode condition are identified as fast as in other conditions unless the access is directly through the graphemic representation.

\section{REFERENCE NOTES}

1. Caramazza, A., \& Brones, I. Semantic classification by bilinguals. Unpublished manuscript, Johns Hopkins University, Baltimore, Maryland 21218.

2. Wolf, J., McCloskey, M., \& Glucksberg, S. Shared vs. separate memory systems: Bilingualism and picture-word proces. sing. Paper read at the Annual Meeting of the American Psychological Association, Toronto, 1978.

\section{REFERENCES}

Baron, J. Phonetic stage not necessary for reading. Quarterly Journal of Experimental Psychology, 1973, 25, 241-246.

Broadbent, D. E. Word frequency effect and response bias. Psychological Review, 1967, 74, 1-15.

Diccionario de la Real Academia Espanola. Madrid: EspasaCalpe, 1970.

Kolers, P. A. Interlingual word associations. Journal of Verbal Learning and Verbal Behavior, 1963, 2, 291-300.

Kolers, P. A. Interlingual facilitation of short term memory. Journal of Verbal Learning and Verbal Behavior, 1966, 5, 311-319.

KuČERA, H., \& Frances, W. N. Computational analysis of present-day American English. Providence, R.I: Brown University Press, 1967.

LOPEZ, M., \& Young, R. K. The linguistic interdependence of bilinguals. Journal of Experimental Psychology, 1974, 102, 981-983.

Macnamara, J. The bilingual's linguistic performance-a psychological overview. Journal of Social Issues, 1967, 23, 58-77.

Rubenstein, H., Garfield, L., \& Millikan, J. A. Homographic entries in the internal lexicon. Journal of Verbal Learning and Verbal Behavior, 1970, 9, 487-494.

SAFfran, E., \& MARIN, O. Reading without phonology: Evidence from aphasia. Quarterly Journal of Experimental Psychology, 1977, 29, 515-525.

Tulving, E., \& Colotla, V. A. Fre recall of trilingual lists. Cognitive Psychology, 1970, 1, 86-98.

Webster's Third New International Dictionary. Springfield, Mass: Merriam, 1971.

Young, R. K., \& NAVAR, M. I. Retroactive inhibition with bilinguals. Journal of Experimental Psychology, 1968, 77, 109-115.

(Received for publication January 15, 1979.) 